\title{
Psychiatric Comorbidity in Alcohol Dependent Outpatients in Tertiary Care Centre
}

\section{Dr Padmini Cherukunnath ${ }^{1}$, Dr Arun M Palayat ${ }^{2}$, Dr Binoo Divakaran ${ }^{3}$ Dr Mohanchandran $\mathrm{V} \mathrm{V}^{4}$}

${ }^{1}$ Assistant Prof. in Psychiatry, Academy of Medical Sciences, Pariyaram Medical College, Kannur, Kerala ${ }^{2}$ Associate Prof. in Psychiatry, Academy of Medical Sciences, Pariyaram Medical College, Kannur, Kerala ${ }^{3}$ Assistant Prof. in Biostatistics, Academy of Medical Sciences, Pariyaram Medical College, Kannur, Kerala

${ }^{4}$ Professor of Psychiatry, Yenopoya Medical College, Mangalore, Karnataka

Corresponding Author

\section{Dr Padmini Cherukunnath}

Assistant Professor in Psychiatry, Academy of Medical Sciences, Pariyaram Medical College (PO), Kannur, Pin Code: 670503. Kerala State, India

Email: ajimini2@gmail.com, Telephone Number: 9447248774 / 9744167466

\begin{abstract}
Alcohol dependence is rising in India, perhaps due to newer and greater stresses related to rapid changes in life-styles. This cross-sectional study was designed to find prevalence of psychiatric co-morbidities in outpatients with alcohol dependence syndrome $(A D S)$ and to analyze relationship between presence of psychiatric morbidity with socio demographic and illness related factors. Data was collected from 100 consecutive outpatients with ADS using structured socio-demographic Performa and semi-structured prevalidated Alcohol intake datasheet. ADS and psychiatric co-morbidities were diagnosed by International Classification of Diseases Diagnostic criteria for research-Tenth Revision. (ICD-10 DCR) Prevalence of psychiatric co-morbidity was 56\%. The most common psychiatric disorder was depressive disorder (39\%). 42.9\% of co-morbid group were unemployed. $80.4 \%$ of co-morbid group had family history of alcohol dependence. $41 \%$ in co-morbidity group preferred drinking alone and cited coping with stress as main reason for first drink. Major maintaining factor for alcohol dependence in co-morbidity group was to relieve negative mood (46.4\%) while it was to relieve craving (56.8\%) in non co-morbidity group. All alcohol dependent patients must be evaluated for co-morbid psychiatric problems. Early identification of co-morbid psychiatric disorders and incorporation of relevant interventions may reduce the morbidity, mortality and relapse in this population.
\end{abstract}

Key Words: Alcohol Dependence Syndrome, Psychiatric Co Morbidity.

\section{Introduction}

Mental disorders are common and pose significant burden on health of developing nations. ${ }^{(1)} \mathrm{Co}-$ morbidity denote those cases in which a 'distinct additional clinical entity' has existed or may occur during the clinical course of a patient having an index disease. ${ }^{(2)}$ Co-morbidity is often associated with poor treatment outcome, severe illness course and high service utilization. Professionals working with co-morbid patients face unique and challenging dilemmas about how to provide the best treatment to address both conditions. (3) Psychiatric co-morbidity is defined as cooccurrence of two psychiatric disorders in any 
combinations in same person. They may occur simultaneously or sequentially ${ }^{(2)}$

While epidemiological research has provided us with figures for national-level prevalence of alcohol use $(21.4 \%)$, it would be prudent to recognize that there are regional differences in prevalence and patterns. The production, availability, consumption and drinking patterns of alcohol have all undergone phenomenal changes in India and have been influenced by the combined effects of globalization, market forces, changing government policies, media promotion and changing values of Indian society. With changing concepts, it is difficult to translate older studies into newer situations. ${ }^{(4)}$ Age of initiation and amount of alcohol intake were significantly associated with positive family history of alcoholism in a dead diction centre in West Bengal. ${ }^{(5)}$

Kerala has the highest per capita consumption of alcohol- nearly 3 times the national rate. (6) Average consumption of alcohol was 3 drinks per day in a study conducted by Indian Council of Medical Research. (7) Such severe alcohol dependence will be associated with high prevalence of psychiatric disorders also. In Kerala, recent prevalence of psychiatric co-morbidity among alcohol dependent inpatients in tertiary care centre was $14 \%{ }^{(8)}$ and $66.59 \%$ in another deaddiction clinic. ${ }^{(9)}$ DSM-IV reminds clinicians that such mood, anxiety or psychotic symptoms that are documented before severe life problems from alcohol or that remain beyond 4 weeks of total abstinence should be carefully evaluated as possible indicators of true co-morbidity with occurrence of two or more independent psychiatric syndromes. (10) Alcohol dependent patients often report that they drink to relieve dysphoric mood, which has been termed "selfmedication." This hypothesis embodies a view of alcoholism in which psychiatric symptoms are primary, with drinking occurring in response to those symptoms. ${ }^{(3)}$ Alcohol induced psychiatric disorders are also not uncommon in this population.
This study attempts to assess the psychiatric comorbidity among alcohol dependent outpatients attending a state medical college psychiatric service and also focuses on socio demographic and illness related particulars of ADS patients with or without psychiatric co- morbidity.

\section{Aims \& Objectives}

1. To measure the prevalence of psychiatric co-morbidity in patients with alcohol dependence syndrome consulting outpatient department of a state medical college hospital.

2. To analyze the relationship of sociodemographic characteristics and illness related variables of alcohol dependence syndrome in patients with and without psychiatric co-morbidity.

\section{Materials \& Methods}

100 consecutive outpatients of either gender aged between 18-65 years diagnosed with alcohol dependence syndrome as per ICD-10 Diagnostic criteria for research ${ }^{(11)}$ were approached. Those patients who had at least one month of abstinence and who had given informed consent were included in the study period of 6 months. Patients with acute alcohol intoxication and withdrawal symptoms, organic brain syndrome, severe physical problems were excluded. All patients were under the management of a consultant psychiatrist. Socio-demographic details, past and family history of Alcohol Dependence Syndrome and psychiatric disorders were recorded. Detailed history and mental state examination was done for all patients to diagnose psychiatric co-morbidities as per ICD-10 DCR. Illness related information such as age at onset of alcohol use, initiating factors, maintaining factors, pattern of alcohol use, presence and type of psychiatric co-morbidity were assessed with alcohol intake datasheet prepared by the investigator. Face-to-face interview rather than self-administered format was used to enhance cultural, language and literacy sensitivity. The draft schedule was given to 5 experts in the field for face validation. Based on 
their suggestions and comments, final schedule was prepared. Treatment was offered for all unmet mental health needs identified in the subjects during study.

Data collected was entered in and later analyzed using the computer program, Statistical Packages for Social Sciences (SPSS) Version 13. Descriptive statistical tools like frequency, percentage, mean and standard deviation were used. Categorical variables were analyzed using Chi- square or Fisher's exact test and continuous variables were analyzed using student's t test. A p value $<0.05$ was considered significant.

\section{Results}

Overall Patient characteristics: The study group comprised of 100 patients whose age ranged from 22 to 60 years, with a mean of 41.38 years and a standard deviation of 9.45 years. Majority (98\%) of the sample were males. Only 2 females were there in the study group who were Hindus in the age group of 41-50 years. Hindus (74\%) dominated the sample followed by Christians (21\%). Muslims constituted only 5\% of the sample. (Figure1). Seventy two (72\%) had primary education and twenty eight $(28 \%)$ had education above primary level. (Table 1)

Prevalence of Psychiatric co-morbidity: $56 \%$ had psychiatric co-morbidity. Depressive disorder constituted $39 \%$ of the psychiatric co-morbidity. Next major co-morbid diagnosis was schizophrenia (27\%). Bipolar affective disorder (13\%) constituted third largest group. Other diagnoses were delusional disorder, adjustment disorder and dissocial personality disorder (7\% each). (Figure 2) $79 \%$ of alcohol dependent patients had co- morbid nicotine dependence.

Factors Associated with Psychiatric Comorbidity: Socio-demographic characteristics of the co-morbid group were compared with the non co-morbid group in Table 1. There was no significant association between presence of comorbidity with age group, marital status, educational status and domicile. Higher unemployment rates $(71 \%)$ were observed in ADS patients with co-morbidity when compared to those without co-morbidity (48\%). Association between employment status and presence of comorbidity was found to be significant (using chisquare test of significance, $\mathrm{p}<0.05$ ). Among those who belonged to nuclear type of family, $70 \%$ had co-morbidity compared to $47 \%$ among those who belonged to joint family. Association between type of family and presence of comorbidity was also found to be significant (using chi-square test of significance $<0.05$ )

Minimum age of initiation of alcohol was 21 years and the maximum age was 51years with mean of 26.56 years and a standard deviation of 5.78 years. Majority (37\%) initiated alcohol in age group of 25-29 years. Difference between mean ages as well as mean age of initiation of drinking in patients with and without psychiatric co-morbidity was not statistically significant (using t-test for difference between two means). Initiation of first drink $(55 \%)$ was with peers and main reasons for initiation was due to peer modeling (37\%) or experimentation (32\%). 55\% of patients first tried alcohol with the expectation of happiness, while $26 \%$ tried it for getting good sleep. Table 2 compares initiating factors of alcohol dependence between co-morbid and non co-morbid groups. There was significant association between presence of psychiatric co-morbidity and main reason for first drink, $90 \%$ of those who cited stress as main reason for first drink had comorbidity. (Using chi-square test of significance < 0.001 ) This relation was statistically significant. ( $p$ $<0.001$, Chi square test)

Most common maintaining factors for alcohol dependence in this sample were craving (44\%), negative mood (30\%) and peer pressure (26\%). Table 3 shows the comparison of maintaining factors between the co-morbid and non co-morbid groups. Among those who cited negative mood as the maintaining factor, $87 \%$ had co-morbidity. Also, $72 \%$ of those who did not have company while drinking were having co-morbidities. Among those who had social sanctioning for alcohol intake, $68 \%$ were having co-morbidities. All the above factors were found to have a 
significant association with co-morbidity (using chi-square test of significance $<0.05$ ).

Other relevant factors were compared between comorbid group and non co-morbid group in Table 4. Among those who did not have any abstinence in the past, $88 \%$ had co-morbid psychiatric disorders. Only $40 \%$ of the early morning drinkers had co-morbid conditions whereas $65 \%$ of those who did not have delirium tremens had comorbidities. Of those who had family history of ADS, $63 \%$ were co-morbid. There was significant association between the relevant factors and comorbid condition (using chi-square test of significance, $p<0.05$ ).

Table: 1 Comparison of Socio- demographic data among alcohol dependent patients with and without psychiatric co morbidity

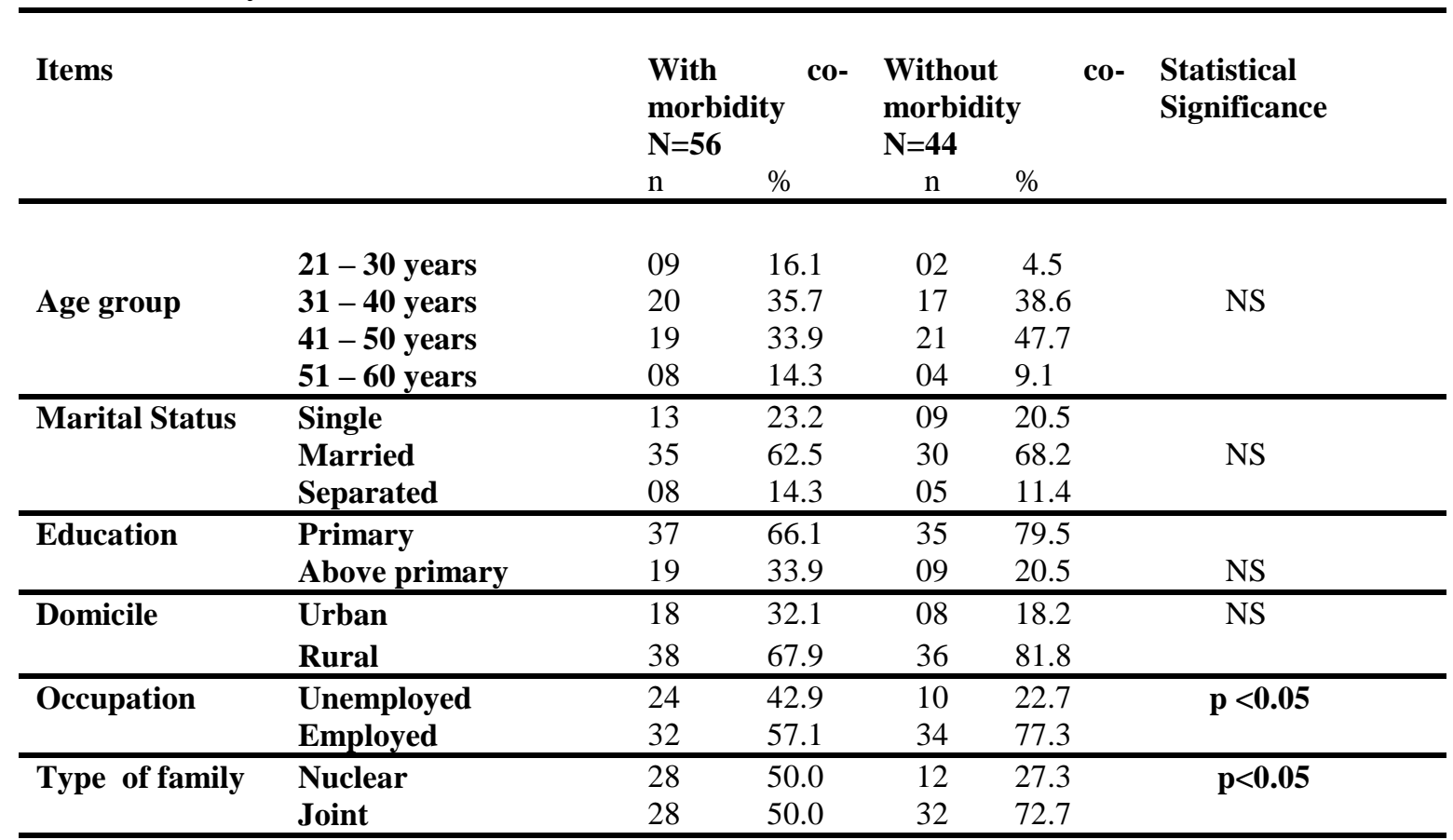

$\mathrm{NS}=$ not significant (the level of significance was calculated by Chi square test which was considered statistically significant when $\mathrm{p}$ value $<0.05)$.

Table: 2 Comparison of Initiating Factors of Alcohol Dependence among Patients with and without psychiatric co morbidity

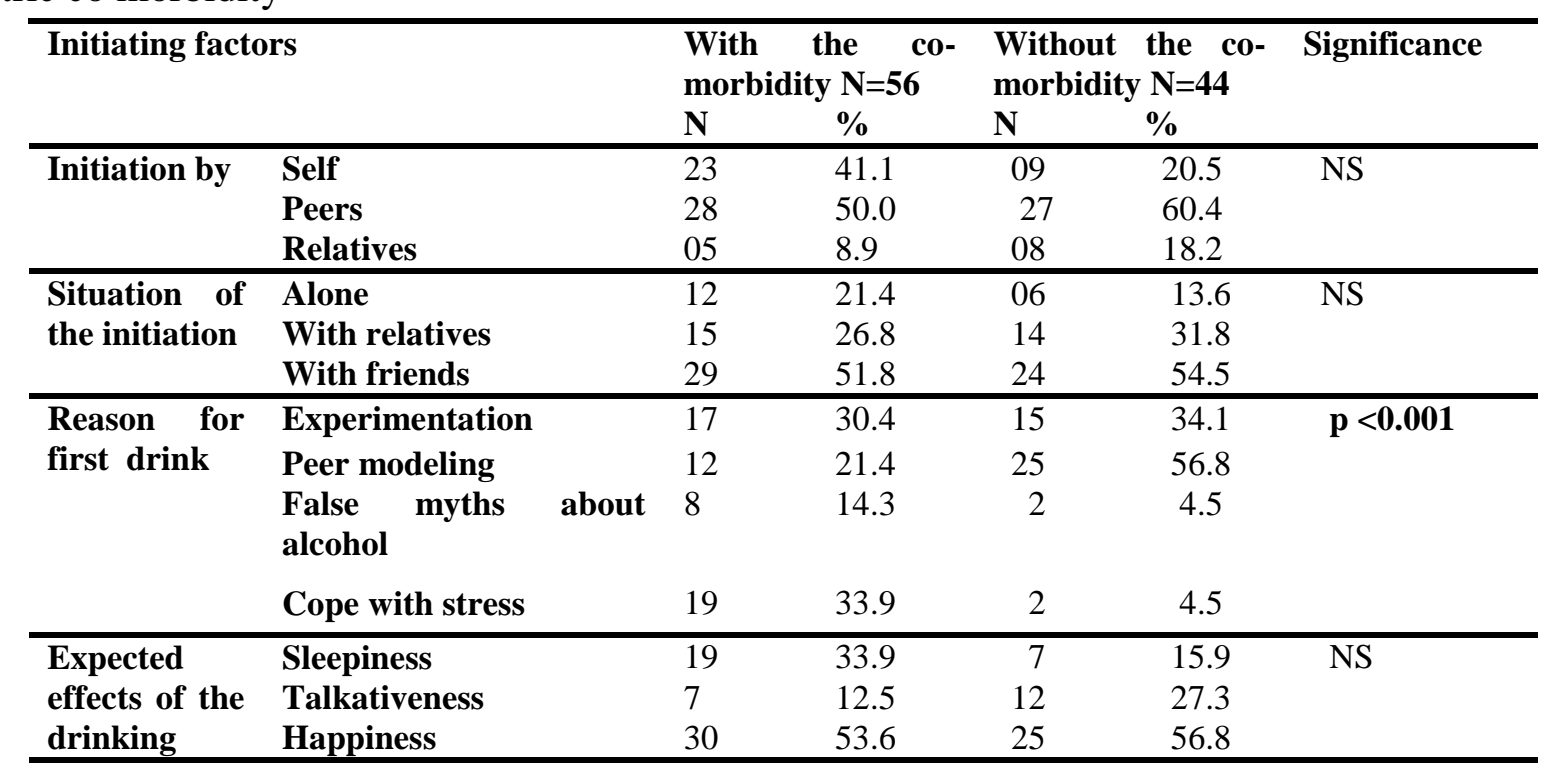

NS = Non significant. The level of significance was calculated by Chi square test which was considered statistically significant when $\mathrm{p}$ value was less than 0.05 . 
Table: 3 Statistically significant maintaining factors of alcohol dependence among patients with and without psychiatric co morbidity

\begin{tabular}{|c|c|c|c|c|c|c|}
\hline \multicolumn{2}{|c|}{ Maintaining Factors } & \multicolumn{2}{|c|}{$\begin{array}{lr}\text { With } & \text { co- } \\
\text { morbidity } & \text { N=56 }\end{array}$} & \multicolumn{2}{|c|}{$\begin{array}{l}\text { Without } \\
\text { comorbidity } \\
\mathrm{N}=\mathbf{4 4}\end{array}$} & \multirow[t]{2}{*}{ Significance } \\
\hline & & $\mathbf{n}$ & $\%$ & $\mathbf{n}$ & $\%$ & \\
\hline \multirow[t]{3}{*}{ Reasons } & Craving & 19 & 33.9 & 25 & 56.8 & $p<0.001$ \\
\hline & Peer pressure & 11 & 19.6 & 15 & 34.1 & \\
\hline & Negative mood & 26 & 46.4 & 4 & 9.1 & \\
\hline \multirow{2}{*}{$\begin{array}{l}\text { Company while } \\
\text { drinking }\end{array}$} & No & 23 & 41.1 & 9 & 20.5 & $p<0.05$ \\
\hline & Yes & 33 & 58.9 & 35 & 79.5 & \\
\hline \multirow{2}{*}{$\begin{array}{l}\text { Social } \\
\text { sanctioning }\end{array}$} & Yes & 34 & 60.7 & 16 & 36.4 & $p<0.05$ \\
\hline & No & 22 & 39.3 & 28 & 63.6 & \\
\hline
\end{tabular}

The test of significance was the Chi square test which was statistically significant when the p value was less than 0.05 .

Table: 4 Other statistically significant factors of alcohol dependence among patients with and without psychiatric co morbidity

\begin{tabular}{|c|c|c|c|c|c|c|c|}
\hline \multirow[t]{2}{*}{ Factors } & & \multicolumn{2}{|c|}{$\begin{array}{l}\text { With the co-morbidity } \\
\qquad \mathrm{N}=56\end{array}$} & \multirow{2}{*}{$\begin{array}{l}\text { Without } \\
\text { morbidity } \\
\mathrm{N}=44 \\
\mathrm{n}\end{array}$} & \multirow{2}{*}{$\begin{array}{l}\text { the } \\
\%\end{array}$} & \multirow[t]{2}{*}{ co- } & \multirow[t]{2}{*}{$\begin{array}{l}\text { Statistical } \\
\text { significance }\end{array}$} \\
\hline & & $\mathbf{n}$ & $\%$ & & & & \\
\hline Abstinence & $\begin{array}{l}\text { Yes } \\
\text { No }\end{array}$ & $\begin{array}{l}41 \\
15\end{array}$ & $\begin{array}{l}73.2 \\
26.8\end{array}$ & $\begin{array}{c}42 \\
2\end{array}$ & $\begin{array}{r}95.5 \\
4.5\end{array}$ & & $p<0.01$ \\
\hline $\begin{array}{l}\text { Early } \\
\text { morning } \\
\text { drinking }\end{array}$ & $\begin{array}{l}\text { Yes } \\
\text { No }\end{array}$ & $\begin{array}{l}23 \\
33\end{array}$ & $\begin{array}{l}41.1 \\
58.9\end{array}$ & $\begin{array}{c}35 \\
9\end{array}$ & $\begin{array}{l}79.5 \\
20.5\end{array}$ & & $\mathrm{p}<0.001$ \\
\hline $\begin{array}{l}\text { Delirium } \\
\text { tremens }\end{array}$ & $\begin{array}{l}\text { Yes } \\
\text { No }\end{array}$ & $\begin{array}{l}15 \\
41\end{array}$ & $\begin{array}{l}26.8 \\
73.2\end{array}$ & $\begin{array}{l}22 \\
22\end{array}$ & $\begin{array}{l}50.0 \\
50.0\end{array}$ & & $p<0.05$ \\
\hline $\begin{array}{l}\text { Family } \\
\text { history } \\
\text { ADS }\end{array}$ & $\begin{array}{l}\text { Yes } \\
\text { No }\end{array}$ & $\begin{array}{l}45 \\
11\end{array}$ & $\begin{array}{l}80.4 \\
19.6\end{array}$ & $\begin{array}{l}26 \\
18\end{array}$ & $\begin{array}{l}59.1 \\
40.9\end{array}$ & & $p<0.05$ \\
\hline
\end{tabular}

NS-Non significant (chi square test was considered statistically significant if $\mathrm{p}$ value was less than 0.05 )

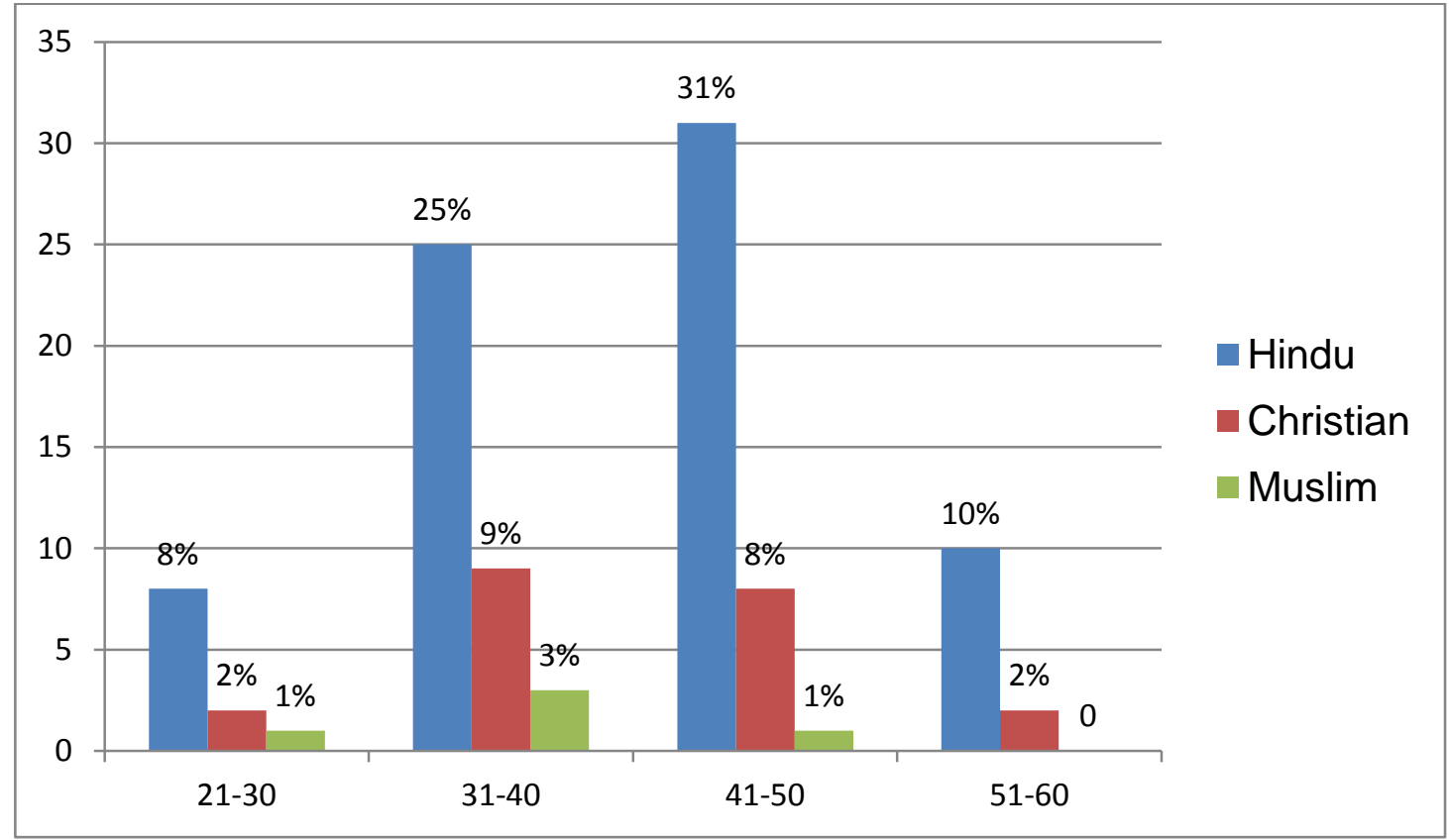

Figure: 1 Age group and religion wise distribution 


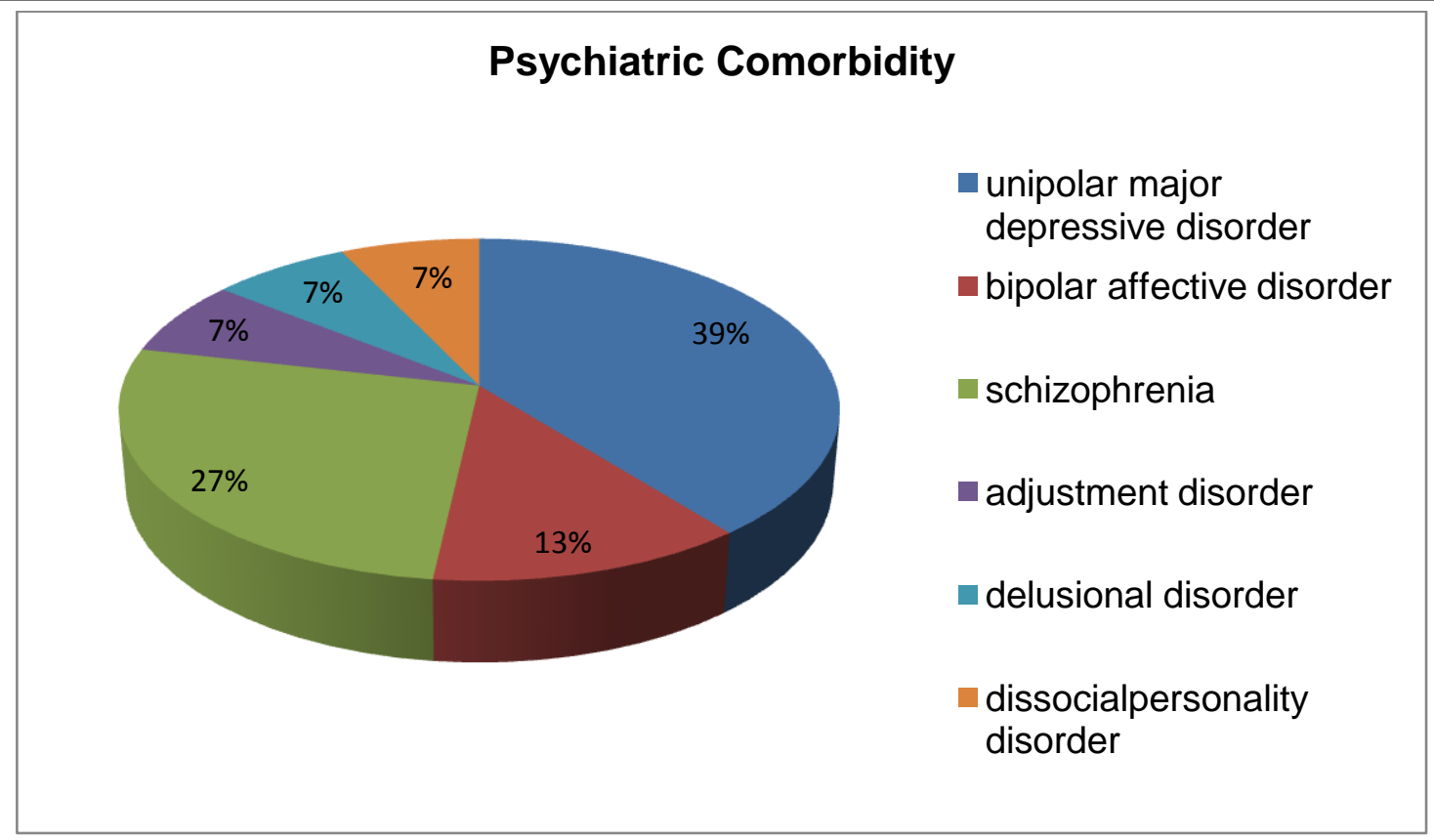

Figure: 2. Psychiatric co morbidity in the sample

\section{DISCUSSION}

In our study, majority of patients were in the age group of 31-50years. Patients with alcohol dependence may take an average of 10 years to develop various medical, neurological or psychiatric complications after the initiation of consumption during early twenties. (3) Other Indian studies also reported similar observations in their sample. ${ }^{(5,8,12)}$

Females constituted only $2 \%$ of the sample in this study similar to another Indian study. ${ }^{(5)}$ A south Indian study concluded that availability of Indian made foreign liquor and living in a village which brewed illicit alcohol were major risk factors for hazardous use in women ${ }^{(13)}$

Both female subjects in our study initiated drinking with their relatives due to false myths about alcohol. Using Indian made foreign liquor and living in a village which brewed illicit alcohol were risk factors for hazardous use in another recent study conducted in rural southern India. ${ }^{(13)}$ The cultural influence in initiating alcohol abuse is an area to be studied in women of specific caste or religious groups.

Hindus (74\%) dominated the sample followed by Christians $(21 \%)$ which was similar to another study. ${ }^{(14)}$ This can be attributed to social sanctioning associated with certain religious customs prevalent in this area, certain occupations and other reasons for cultural and social sanctioning. In many tribal societies, this may take place relatively early, but typically in the context of a traditional ritual (as opposed to drinking for pleasure, as in developed countries). Low prevalence in Muslims (5\%) can be explained as a result of the religious prohibition. Jammu and Kashmir records the lowest alcohol consumption. Experts attribute this fact to religious factors. ${ }^{(1)}$

A low educational status was found among $71 \%$ of the individuals in this study. Another Indian study also reported maximum alcohol dependence $(55.9 \%)$ in illiterates. ${ }^{(15)}$ Education was protective against development of alcohol dependence in another Indian study. ${ }^{(12)}$ A significant proportion of patients in the co-morbid subgroup were unemployed. This may be due to higher severity of alcohol consumption, morbidity and occupational dysfunction in this subgroup of patients. Alcohol dependent patient living in a joint family had fewer co morbidities in this sample. This was similar to other Indian studies. $(12,16)$ Poor social support has been found to be etiologically linked to psychiatric co-morbidity ${ }^{(3)}$ However, psychiatric morbidity itself may reduce the level of the available support. This study being 
cross sectional in nature cannot comment on the cause and the effect relationship.

Majority (63\%) of those with family history of alcohol dependence were having co-morbid psychiatric disorder similar to another Indian study. ${ }^{(5)}$ Psychiatric disorder can co-exist with alcoholism either by chance or because a family history of alcoholism increases risk of its occurrence in psychiatrically ill patients. Some evidence is available to support the possibility of familial transmission of both bipolar disorder and alcoholism. ${ }^{(17)}$ Detection of family history can be in many aspects useful for establishing clinical subtypes, predicting specific (psychiatric, social or medical) complications, or helping to find the most relevant treatment modality. ${ }^{(18)}$

Initiation of first drink was mostly with peers (55\%). Alcohol consumption among men often takes the form of binge drinking, typically outside home, with other men, usually with a goal to get drunk. Thus excessive drinking celebrates male courage, maturity and ability to take risks. (19) Main reasons for initiation were due to peer modeling $(37 \%)$, experimentation $(32 \%)$ or to cope with stress. First drink was predominantly tried with expectation of happiness $(55 \%)$ while $27 \%$ tried for getting good sleep. Co-morbid group cited coping with stress as main reason for first drink. This relation was statistically significant. In many countries, drinking and intoxication may have important social meanings, such as coping with stressful situations. ${ }^{(1)}$

Most common maintaining factors for alcohol dependence in this sample were craving (44\%), peer pressure $(26 \%)$ and negative $\operatorname{mood}(30 \%)$. They show statistically significant differences between 2 groups. Among those who used alcohol to relieve negative mood, majority (87\%) were comorbid. Alcohol use may be an attempt to selfregulate symptoms of distress, such as anxiety, fear or feelings of depression (negative affect pathway). Drinking in order to cope with negative emotions is related to high levels of neuroticism and sensitivity to anxiety, low level of agreeableness and a negative self-image. ${ }^{(20)}$
Among those who continued alcohol use to relieve craving, majority (57\%) belonged to non comorbid group. Also, majority (88\%) of those with non abstinence were co-morbid. Craving a common determinant of relapse has been shown to reduce with increase in length of period of abstinence. $\left.\quad{ }^{(4,}{ }^{14}\right)$ Precipitants of relapse (dysfunction, stress and life events) differ among alcohol dependent patients. ${ }^{(4)}$

Among those who preferred drinking alone, majority $(72 \%)$ had co morbid psychiatric disorders. In another Indian study, hazardous drinkers tended to drink alone in bars and preferred non-commercial alcoholic beverages, which are cheaper and have relatively high alcohol concentration. Hazardous drinkers do not only consume large amounts of alcohol, but also do so in high-risk patterns, such as drinking alone and bingeing. Beverage choice was related to socioeconomic status, with cost and ease of access being key determinants. ${ }^{(19)}$

Majority $(60 \%)$ of those with early morning drinking were significantly non co-morbid. Public measures like the restriction of advertising and promotion of alcohol, timings of alcohol sale and location of outlets might help in the long run to prevent as well as minimize this problem. ${ }^{(13)}$

A large proportion of subjects of the present study (56\%) had co morbid psychiatric diagnosis. A great variation in the co-morbidity with alcohol dependence (3-98\%) has been reported. ${ }^{(4)}$ This is due to wide variation in study methods used, including how alcohol use and various disorders are defined, as well as in sampling strategies. These variations make comparisons difficult. But prevalence of psychiatric co morbidity has been increasing recently. $(12,21,22)$ This may reflect actual increase or more reporting due to recent trend of increased social sanctioning especially in females and associated with binge drinking during social customs. This is particularly relevant in Kerala.

In this study, depressive disorder constituted the majority of the psychiatric co- morbidity (39\%). Previous Indian studies have also reported similar prevalence of depressive disorders in alcohol 
dependent sample. ${ }^{(16,23)}$ Recent Indian studies also show increasing trend of co morbid depression. ${ }^{(12,21,22)}$ Major limitations in existing work are use of small clinical samples and crosssectional nature of studies. ${ }^{(4,24)}$ The former was rectified but the latter persist in our study also.

Next major co morbid diagnosis was schizophrenia $(27 \%)$. These findings support an earlier study. ${ }^{(21)}$ But as reviewed by Murthy $\mathrm{P}$ et al in 2010, ${ }^{(4)}$ other Indian studies suggest that substance use co morbidity in schizophrenia is low, and is an important contributor to better outcome in schizophrenia in developing countries like India. ${ }^{(25)}$

Bipolar affective disorder (13\%) constituted the third largest group. Other Indian studies have also revealed such prevalence. ${ }^{(12,16,21)}$ Patients with bipolar disorder may drink to alleviate both mania and depressive symptoms, though evidence indicates that the greatest risk for heavy drinking occurs during the manic phase of their illness. Diagnosing bipolar disorder in alcohol dependent patients can be particularly challenging. Several factors, such as under reporting of symptoms (particularly symptoms of mania), complex effects of alcohol on mood states, and common features shared by both illnesses (e.g., excessive involvement in pleasurable activities with high potential for painful consequences) reduce diagnostic accuracy. ${ }^{(17)}$

Other diagnoses were delusional disorder, adjustment disorder and dissocial personality disorder (7\% each). The number of cases of individual psychiatric disorders in our study was insufficient for further statistical analysis.

Prevalence of personality disorders has been uniformly reported to be higher in alcohol dependence ${ }^{(20)}$. Unfortunately; studies of clinical populations have shown a striking divergence regarding the prevalence of personality disorders (24-78\%) in alcohol dependent patients. Similarly, types of personality disorders, including their combinations, found to be related to alcoholism are very heterogeneous. The disparity may be due to the difference in the study groups, the educational status and the cultural differences between the different study groups. ${ }^{(20)}$ Clinicians should work with patients to differentiate between symptoms that are attributable to alcohol dependence and symptoms that are attributable to dissocial personality disorder. It is likely that Axis - II co morbidity predisposes person to other types of psychiatric disorders. However a small sample does not permit any generalization.

Anxiety disorders do not seem to occur at much higher rates among alcohol dependent patients in this study similar to other studies. ${ }^{(9,12)}$ This might be because of our use of unstructured interview. A large proportion of subjects of present study had multiple co morbid diagnosis. Similar figures were also reported in other studies. ${ }^{(14)}$ This further illustrates the heterogeneity of patients with alcohol dependence and implies that clinician should not stop after making one or two diagnoses.

A complex interaction of etiological factor determines e outcome of any disorder. Patients at a tertiary centre are likely to have more severe presentation of the disorder. But severity of alcohol dependence and co-morbid psychiatric disorders were not measured in this study which limits the assertion of any such associations. Together, these findings suggest that patients diagnosed with alcohol use disorder should undergo thorough psychiatric assessment for comorbid psychiatric disorders. Conversely, patients seen in psychiatric settings should be routinely evaluated for the presence of alcohol use disorder. Presence of co morbid psychiatric disorders in alcohol dependent patients has clinical and prognostic implications.

Limitations of this study: This was a cross sectional study from a hospital set up which limits the generalizability of the observations. Further the current study did not use any structured instruments for assessing patients. A large scale community based study in the same area with validated instruments and questionnaires will give an actual picture of the problem in this community.

Strengths of this study: Cross sectional evaluation of 100 patients with alcohol 
dependence was done. This was a decent number for any time limited cross sectional research. The study has helped to understand the importance of evaluation of co- morbid psychiatric diagnosis in patients with alcohol dependence.

Conclusion: Our study highlights the fact that psychiatric co-morbidities are highly prevalent in alcohol dependence. High co-morbidity of depressive disorders and other major psychiatric disorders among patients with ADS adds to the dysfunction, morbidity and mortality among these patients. These findings substantiate the need for the development of the specialized dual diagnoses programs treating both index and co morbid conditions and suggests that additional specialization may be required to address the diagnostic group differences in the characteristics of the co morbid alcohol disorder. Public measures like discouraging initiation to drink particularly in individuals at high risk (e.g. family history of alcoholism), might help in the long run to prevent as well as minimize this problem.

\section{Acknowledgement}

We would like to thank Ms. Vini. K. K. and Ms. Sherry. A. A. for their kind collaboration in this study.

Conflict of Interest: None declared.

Ethical Approval: The study was approved by the institutional Ethics committee.

\section{References}

1. Vikram Patel. Alcohol Use and Mental Health in Developing Countries. Annual of Epidemiology.2007; 17(S): 87-92.

2. Feinstein AR. The pre therapeutic classification of co morbidity in chronic disease. Journal of Chronic Disease. 1970; 23: 455-68.

3. Petrakis IL, Gonzalez G, Rosenheck R et al. Co morbidity of Alcoholism and Psychiatric Disorders - An Overview. Alcohol Research \& Health. 2002; 26(2): 81-89.
4. Murthy P, Manjunatha N, Subodh BN et al. Substance use and addiction research in India. Indian Journal of Psychiatry. 2010; 52(S): 189-199. 2

5. Sarkar AP, Sen S, Mondal S et al. A study on socio-demographic characteristics of alcoholics attending the de-addiction center at Burdwan medical college and hospital in West Bengal. Indian Journal of Public Health. 2013; 57(1): 33-5.

6. The extent of problem of Mental Health in Kerala. [Internet] Kerala State Mental Health Authority; 2010. [Cited 2015 Nov 20]. Available from: http://www.ksmha.org/kerala.htm.

7. National Institute of Medical Statistics, Indian Council of Medical Research (ICMR). IDSP Non- Communicable Disease Risk Factors Survey, Kerala, 2007-08. New Delhi: National Institute of Medical Statistics and Division of NonCommunicable Diseases, Indian Council of Medical Research; 2009.

8. Davis Manuel, Linus Francis, K. S. Shaji .Prevalence and risk factors for psychiatric co-morbidity in patients with alcohol dependence syndrome. Journal of Evidence based Medicine and Healthcare. 2015; 36(2): 5704-5711.

9. Kattukulathil S, Kallivayalil RA, George $\mathrm{R}$, Kazhungil F. Psychiatric comorbidity in alcohol dependence: a cross-sectional study in a tertiary care setting. Kerala Journal of Psychiatry 2015; 28(2): 156-60.

10. American Psychiatric Association. Diagnostic and statistical manual of Mental Disorders IV. Washington DC: American psychiatric association; 1994.

11. World Health Organization. International Classification of Diseases and Related Health Problems. Diagnostic criteria for research 10th Revision. 2nd ed. Geneva: World Health Organization; 2005.

12. Singh NH, Sharma SG, Pasweth AM. Psychiatric co-morbidity among alcohol 
dependents. Indian Journal of Psychiatry. 2005; 47(4): 222-224.

13. John A, Barman A, Bal D et al. Hazardous alcohol use in rural southern India: nature, prevalence and risk factors. Natural medical journal of India.2009;22(3):123-5.

14. Chand P, Naveen CK, Murthy P et al. Addressing alcohol addiction: lessons from a hospital based audit. Indian Journal of Medical Research. 2013; 137(2): 394396.

15. Meena, Khanna P, Vohra AK et al. Prevalence and pattern of alcohol and substance abuse in urban areas of Rohtak city. Indian Journal of Psychiatry.2002; 44: 348-52.

16. Vohra AK, Yadav BS, Khurana H. A Study of Psychiatric Co morbidity in Alcohol Dependence. Indian Journal of Psychiatry. 2003; 45(4): 247 -250.

17. Sonne SC, Brady KT. Bipolar Disorder and Alcoholism. National Institute on Alcoholism and Alcohol Abuse. 2002.

18. Gururaj G, Murthy P, Rao GN, Benegal V. Alcohol related harm: Implications for public health and policy in India. Bangalore: NIMHANS; 2011.

19. Gaunekar G, Patel V, Rane A. The impact and patterns of hazardous drinking amongst male industrial workers in Goa, India. Social Psychiatry \& Psychiatric Epidemiology. 2005; 40: 267-275.

20. Mellos E, Liappas I, Paparrigopoulos T. Co morbidity of Personality disorders with alcohol abuse. International Journal of Experimental and Clinical Pathophysiology and Drug Research. 2010; 24(5): 761-769.

21. Shantna K, Chaudhury S, Verma AN et al. Co morbid psychiatric disorders in substance dependence patients: A control study. 2009; 18 (2): 84-87.
22. Kumar V, Dalal PK, Trivedi JK. A study of psychiatric co morbidity in alcohol dependence. Delhi Psychiatry Journal. 2010; 13(2): 291-294.

23. Khisty N, Raju MSV, Tampi UR. A study of co morbid psychiatric disorder in alcoholism. Indian Journal of Psychiatry. 2001; 43.

24. Srivastava A, Sreejayan K, Joseph AM et al. Indian research on co morbidities. Indian Journal of Psychiatry. 2010; 52(11): S189-S199.

25. Thirthahalli J, Venkatesh BK, Gangadhar BN. Psychosis and illicit drug use: need for cross cultural studies. Acta Psychiatrica Scandinavica. 2008; 118: 86. 